\title{
AN INTEGRATED TECHNOLOGICAL TRACEABILITY MODEL IN THE OLIVE GROWING PRODUCTION CHAIN
}

\author{
Ferruccio Giametta, Giuseppe Sciarrone
}

\section{Introduction}

As is well known, the agrofood sector has been hit by scandals and frauds in the last few years. This has resulted in a growing interest in notions including quality, food safety and foodstuff origin on the part of consumers.

A completely different approach to the problem, as highlighted by the above examples, suggests to utilize, for the time being, the definition given by the Italian "Academy of Georgofili:

"Chain traceability means identifying all the businesses contributing to the production of a food product. Such identification relies on monitoring the flows of materials 'from farm to fork", i.e. from the producer of the raw material to the end consumer" [2].

The above mentioned European rules resulted in EC Regulation 178 of January 28, 2002 which set forth the general principles and requirements of an EU food law by establishing procedures and by setting up the European Food Safety Authority (EFSA) [1].

The present study, which has been conducted on a sample of olive growing farms/oil mills, has highlighted that, in spite of the requirement to enforce the above EC regulation 178 by January $1^{\text {st }}, 2005$ (subsequently extended to January 1st, 2006), a poor attention is still attached to the issue of traceability at a community level where many gaps still remain in terms of information on such systems.

Problems have been found both from a systemic point of view (in terms of capability to trace and track each phase of the processes occurring along the olive growing and production chain), and from the point of view of the optimization of the management of the different activities, from the collection of information related to the production lots throughout all the phases

\section{Paper received 17.02.2008; accepted 20.06.2008}

Dr. Ferruccio Giametta, Ricercatore Confermato, Dipartimento SAVA, Università del Molise. Dr. GIUSEPPE ScIARrone, Dottore di Ricerca, Dipartimento STAfA, Università "Mediterranea" di Reggio Calabria.

The authors contributed on an equal basis to the drawing up of the present study. of the production process, to the supply of updated data in terms of inventories, processes under way, yields, etc., to the planning and management of each individual production operation in a view to obtaining benefits in terms of rationalization, savings and quality level.

Now, in light of the above, traceability is clearly intended to guarantee food safety [3].

Under the above regulations it can be appropriately stated that the traceability of food products accounts for a reliable tool:

- to manage the states of emergency following food crises, not only by streamlining targeted recalls from the market of the food products considered to be a risk for human health (providing also useful information to both consumers and officials in charge of monitoring and control operations), but also, and perhaps more importantly, to contain potential additional spreading of the damage as it enables to isolate the "harmful" chain of production (EC Reg. 178/2002, articles 12, 28).

- to introduce transparency in the production chain (as explicitly suggested for the beef production chain by Reg. 1760 of 07.17.2000, subsection 4).

- to raise producers' awareness of the need to adopt adequate systems of traceability to improve the transparency of their productions.

- to contribute to the ever growing need of adequate controls by competent authorities on the enforcement of the traceability systems as a support to the inspection operations carried out by the Local Health Authorities in their respective areas [4].

The present work is focused on the analysis and on the use of systems of traceability in the olive growing/olive oil production and supply chain of an Italian Region: Calabria. It has relied on a preliminary indepth territorial survey meant to select those olive growing farms considered to be a representative sample of the olive-growing reality in the area under study. The above survey has been followed by the analysis of the different processing phases which envisage one or more operations: from in-field olive harvesting operations to oil mill olive handling and processing. 
A detailed analysis of the productive processes has been carried out relying on the so-called "dynamic lot", defined as the unit of product processed (either directly or indirectly) in a unit of time (usually one day), as a function of the specific features of the farms in question (orographic features, level of mechanization, etc.). The many data collected have been used to implement a specific software designed to monitor all processing and production phases. Relying on the acquisition of data (input) related to the olive-growing sector under study, the above software has implemented (output) innovative labelling systems (barcode labels) which allow for a ready and rapid data processing on the part of operators and provide exhaustive information on the origin of the product in question.

\section{Materials and methods}

\subsection{Flowchart of the olive growing sector}

To put in place the traceability system of the production chain in question it has been first of all necessary to define contents, objectives and boundaries of the system itself. This has been done by defining the flowchart of the olive production chain as shown in Figure 2.

The above flow-sheet includes:

- an indication of the size of the production chain;

- ingredients, additions, additives used;

- the path travelled by the raw material and the name of the businesses involved.

To this end, the businesses contributing to the production of the end product have been defined under the scheme given in Fig. 2. Also the production lots undergoing the same processing steps have been identified.

The chart below identifies all the businesses involved in the traceability system tracing the path of the main suppliers of the raw material, starting from the " $N$ " businesses supplying additives, additions and all those major products/services included in the production process. The above chart also includes the " $M$ " businesses, i.e. the olive growers. Under the method adopted by this study all the businesses included in the flowchart must be involved in the traceability of each and every product/service.

All the " $N$ " and " $M$ " businesses of the traceability system in question have subscribed to a declaration of intent whereby they have undertaken to guarantee the identity of the flows of the production chain under study.

Production chain traceability is not broadly referred to the overall production of a business. Quite the contrary, traceability is referred to each unit of product which has to be materially and individually identified [6].

As a result the management of the production processes must be done "for lots" so as to monitor,

for each one of lots produced daily, all the operations (already carried out and to be carried out) likely to contribute to the output of the lot in question based on the assumption that the level of mechanization and of organization of the work site remain unchanged.

\subsection{A model to determine the lot in the olive growing/oil production chain}

On the basis of the above remarks, the present study has focused on the definition of a logistic unit (the lot) as an initial unit of reference for all infield

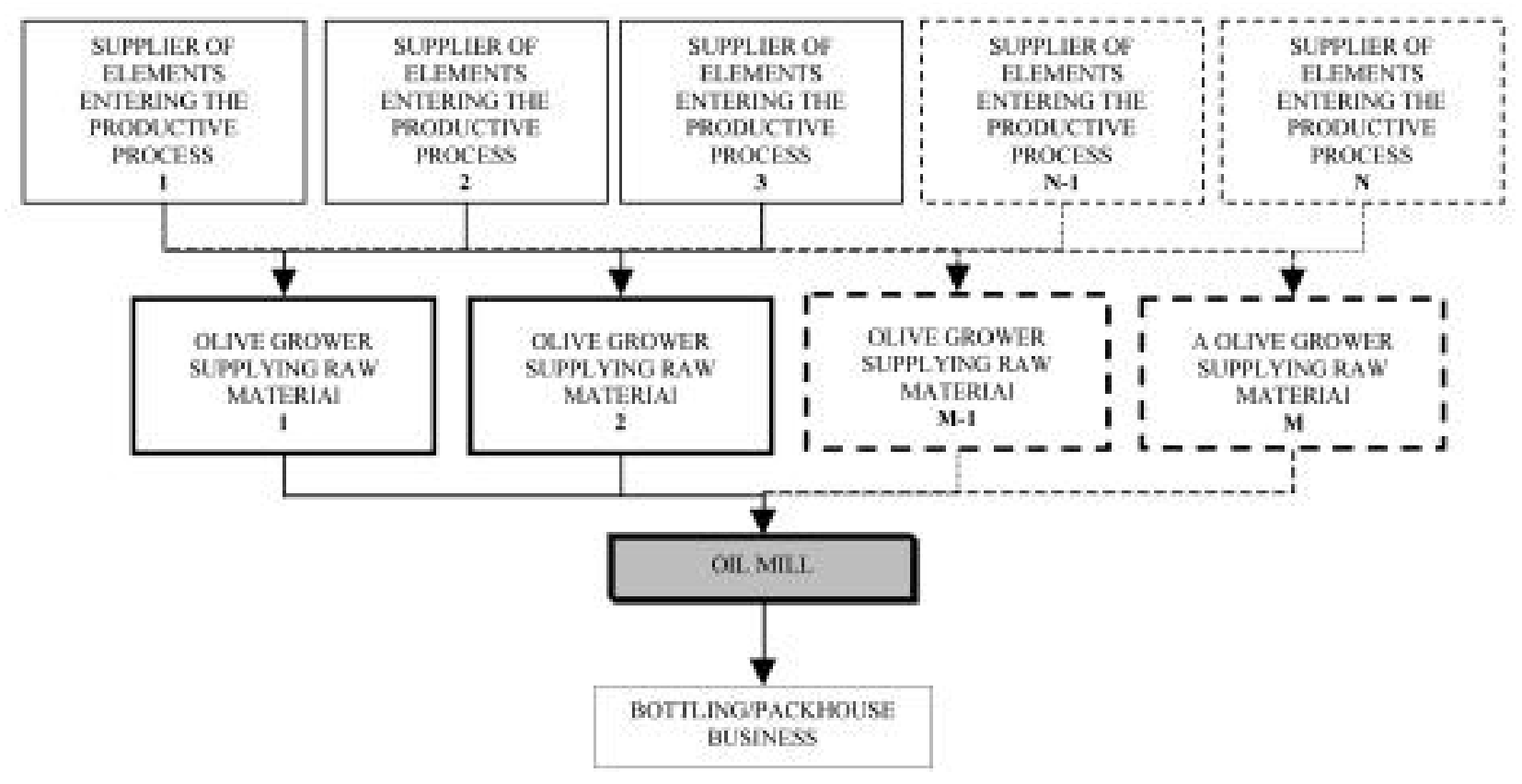

Fig. 1 - Flow- sheet of the olive growing/olive oil production chain 
cropping operations, harvest included. On the grounds of the results of a three-year a research effort a correlation model (which is being finalized) has been defined which is intended to determine on a quantitative basis (surface) the lot containing the most important data that accompany the production process, from the olive grove to the oil mill.

Given the heterogeneous nature of the olive growing sector under study, the determination of the $d y$ namic lot $\left(L_{d}\right)$ can depend on the following variables:

$$
L_{d}=f\left(i, t_{j}, s, c, M_{a}, O_{l}\right)
$$

where:

$i=$ soil slope;

$t_{j}=$ planting typology;

$s=$ shape and layout of the groves;

$c=$ plant size;

$M_{a}=$ level of mechanization;

$O_{l}=$ level of organization of the work site.

The parameters contained in (1) spell out the peculiarities of the olive grove under consideration. As a result, also the size of the lot will necessarily vary and its dimensions will be determined case by case.

\subsection{A traceability model for monitoring and managing productive flows: a dedicated software}

After splitting the surface of each farm into homogeneously sized lots, as already mentioned, a data survey form has been drawn up for each phase for gathering information on all the elements required to characterize the phase in question and detect the origin (timing and places) of each lot of fruit. The above survey forms have allowed to get a global view of all the productive process while registering the details of the individual operations to highlight any errors to be avoided in the future. For example, in line with the logic described in Fig. 2, it has been observed that before harvesting operations a check must always be made in terms of compliance with safety intervals, if any.

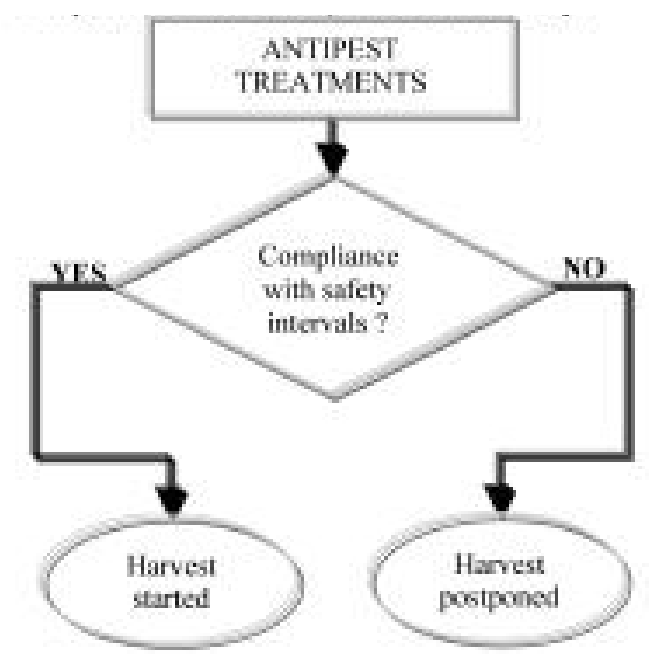

Fig. 2 - Procedure to check safety intervals.
One of the major criticalities in the model of traceability under study occurs at the time of raw material (olives) processing at the oil mill where sometimes olives can mix with other non traced olives, i.e. drupes with different features (acidity, number of peroxides, etc.) that can happen to mix with more valuable lots.

Therefore it has been decided to implement a system meant to check that the raw materials arriving at the oil mill are those actually processed there.

This kind of check has been performed by analysing samples from the different lots unloaded at the oil mill at different times and in various modalities in line with the logic given in Fig. 3.

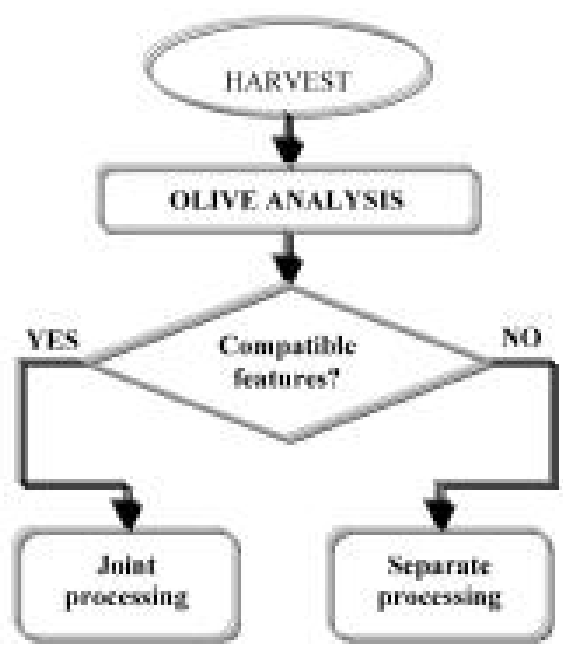

Fig. 3 - Logic scheme of the processing procedure.

The analysis of the samples of olives arrived at the oil mill has been conducted by extracting from $5 \mathrm{Kg}$ of olives from each lot about $600 \mathrm{~g}$ of oil by means of a mini oil mill.

The oil extracted has been then analysed in search for parameters including acidity and number of peroxides. On the basis of EEC Regulation 2568/91 (amended by EC Regulation 1989/03 for olive oil commercial ranking) the analyses conducted have allowed to split the lots analysed into classes as reported in Table 1 [10].

The decision to opt for just two kinds of analysis has been dictated by the need to obtain qualitative in-

\begin{tabular}{|c|c|c|c|}
\hline Class & $\begin{array}{c}\text { Olive oil } \\
\text { category }\end{array}$ & $\begin{array}{c}\text { Acidity } \\
{[\%]}\end{array}$ & $\begin{array}{c}\text { Number of } \\
\text { peroxides }\end{array}$ \\
\hline $\mathbf{1}$ & Extra vergin & $\leq 0.8$ & $\leq 10$ \\
\hline $\mathbf{2}$ & Vergin & $\begin{array}{c}0.8<\mathrm{a} \leq \\
2.0\end{array}$ & $10 \div 15$ \\
\hline $\mathbf{3}$ & Lampante & $>2.0$ & $>20$ \\
\hline
\end{tabular}

TABLE 1 - Chemical-organoleptic features of olive oil. 
formation as soon as possible (about two hours) in a view to:

- shorten at most the warehouse stay of harvested olives and avoid fermentation processes;

- separating the olive lots before processing operations without delaying the next phases of the productive process.

The qualitative analyses have been performed by means of a portable analyzer ( Fig. 4) which has allowed for a ready, rapid and direct assessment of the acidity level and of the number of peroxides of the sample of olive oil extracted.

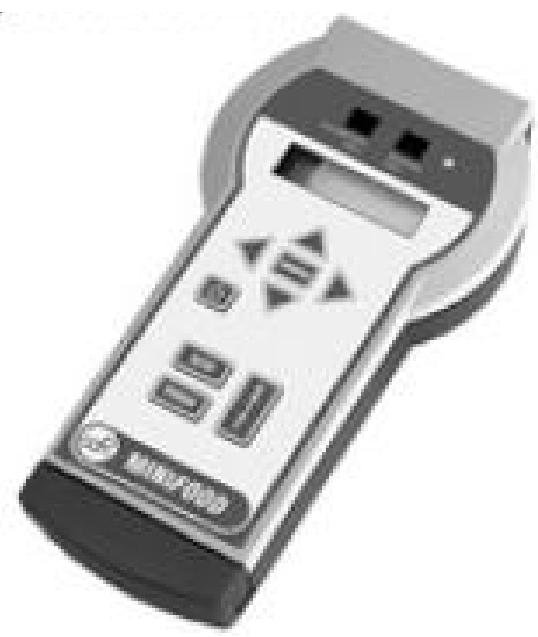

Fig. 4 - Portable analyzer to assess acidity level and number of peroxides.

Olive oil acidity level is given by the amount of free fatty acids resulting from the hydrolytic degradation of triglycerides. Therefore the chemical analysis carried out to assess the acidity level of olive oil allows for one first assessment of a parameter which is also a crucial indicator of the genuineness of the product.

The chemical analysis performed to determine the number of olive oil peroxides allows to establish the quality and the state of preservation of the same oil: the smaller the number of peroxides, the higher the fat quality and the state of preservation of the oil in question. Indeed the number of peroxides present in olive oil account for the level of primary oxidation and hence for the tendency to go rancid of the same oil [11].

\section{Traceability software}

To optimize the flow of information across the different subjects it has been decided to implement a computer system meant to process the data entered by each operator of the olive chain and turn them into useful information addressed to consumers according to the scheme illustrated in Fig. 5 [7].

The traceability software proposed, as illustrated in Fig. 7, is in line with the logic of art. 18 of EC Regulation 178/2002 and enables to document all the chain activities, thus allowing businesses to demonstrate

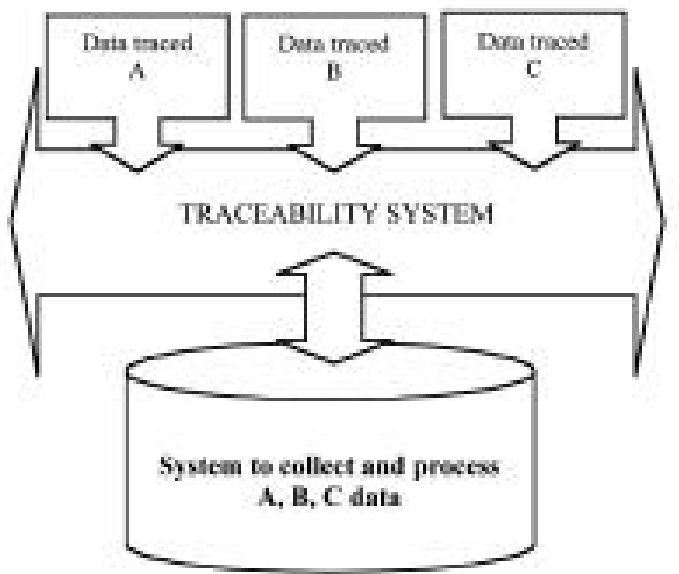

Fig. 5 - Representation of the data processing modality.

their compliance with the rules in force in terms of traceability.

The system adopted allows to describe and document:

- organization, methodology, techniques and tools utilized to plan and monitor activities;

- resources and responsibilities in terms of the quality of the product [5].

Information on all products can be processed and transferred into barcode labels or, via the web, onto customized collective portals. A computer system is presently being developed which is expected to:

- coordinate the flows of information on farming chains traceability;

- allow the backtracking of each individual lot of produce;

- indicate the accompanying documents (barcodes included) required to identify the lots in question;

- manage the chain logistics (travel of the traced lots across the various operators).

The primary objective of the present study has been the detection of any mismatches, i.e. handling or registration errors likely to impair the tracking of the product in question. When these errors occur the portion or the lot of product in question must be excluded not only from the traceability line, but also from the food chain to suppress any sources of risk in compliance with EC Reg. 178/2002 articles 3, 6, 7, 8.

The software in question has been implemented mainly to respond to the requirements of documentability and checkability.

Documentability has been obtained by means of a precise description of the productive process and of the control systems together with the indication of the procedures which define the operational procedures of the production process under consideration.

Checkability has been obtained by an accurate registration (in specific forms) of the activities carried out with relevant indication of both outcomes and people in charge. In line with the parameters given in Fig. 6, it has been possible to obtain a complete traceability of both operations and treatments given to the 
product during the different processing phase.

After data input, the software processes a 14-digit barcode which encompasses all the data of the product, from the lot of origin to the oil mill processing operations as required by the model shown in Fig. 6. In Visual Basic Environment the software (see Figure 7) turns the text strings into an alphanumeric format thus producing the desired code.
This barcode allows for a rapid data scanning and acquisition by means of a laser gun scanner. [8].

Barcode scanners mimic keystrokes entered via a keyboard: after deciphering the barcode they pass the information on to the computer where it is displayed the software can be used also on individual workstations and can be shared in a Windows Environment network. The database, which is structured in an user-

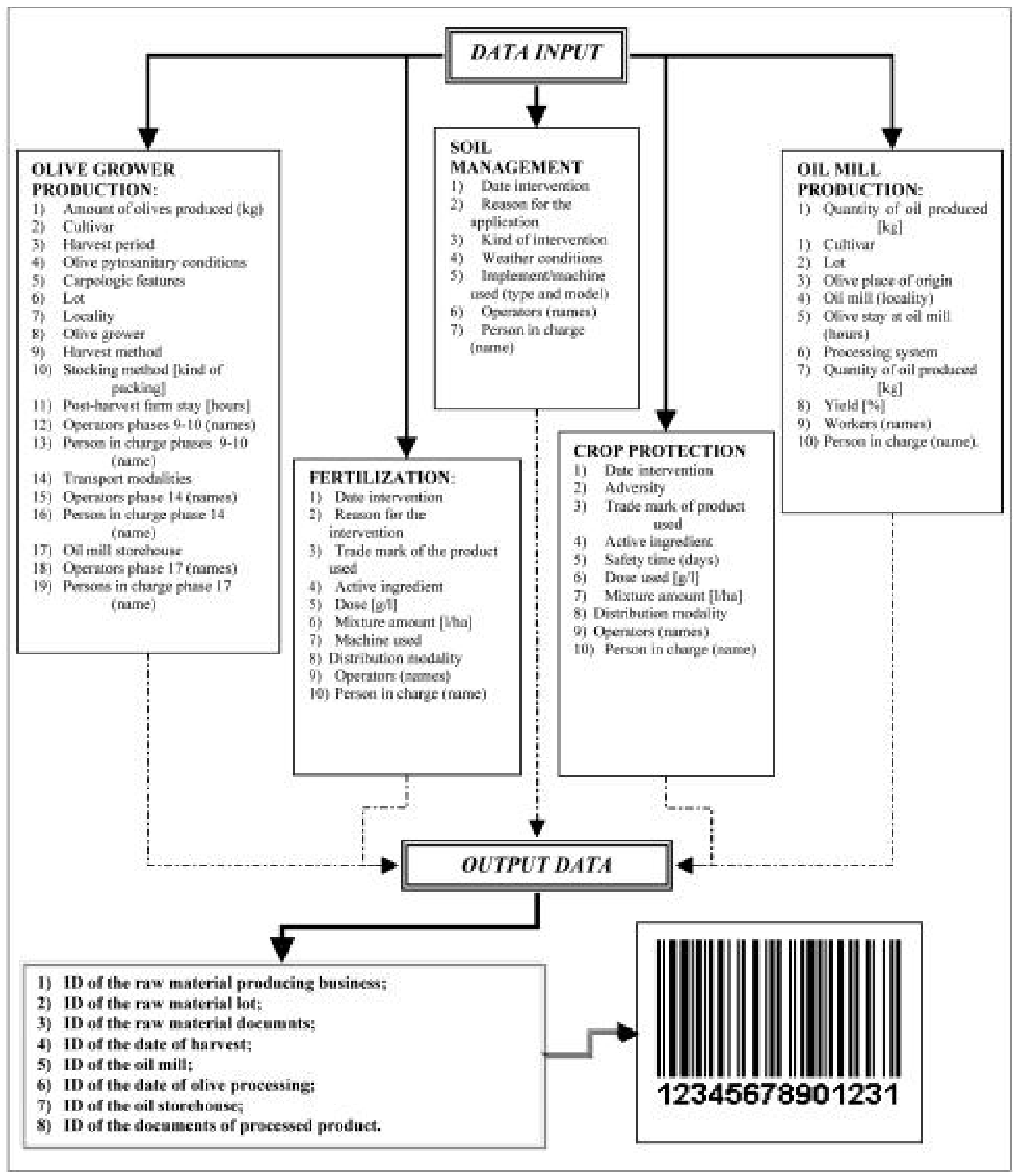

Fig. 6 - Model of data implementation used in the olive-oil processing chain. 
After this phase the surfaces have been compared to actually processed (infield measurements) under different conditions ranging from variation in slope to change in cultivars and soil (slope and planting layout and distance).

\section{Conclusions}

The filed of application of a traceability system reflects the definition of width (from the beginning to the end of the production chain) and of depth (i.e. the number of products and components of the production chain) of the agrofood production and supply chain. In other words, a traceability system is intended to identify all the farms/businesses contributing to the production of the product in question (including their organizations and flows of materials) as well as the relevant products or components whose tracing and backtracking are required to put in place the traceability system in question. The definition of the context of application is up to the parties involved since the design and the implementation of the system of production chain backtracking are influenced by the product itself (whose documented production chain has to be defined) as well as by the need to comply with the laws and regulations in force.

From this perspective the first step to implement a system for production chain backtracking consists in sharing some aspects including the definition of the product/s, or of their relevant components, the management and the flows of the materials involved in production. Indeed traceability does not mean to trace each and any element; quite the contrary, it means to trace all the elements deemed to be useful and necessary [9].

Defining a tracking system therefore means to make a series of choices concerning:

1. the parameters to be defined inside the farms/ businesses involved (products, raw materials, environmental storage conditions);

2. the pieces of information the farm/business wants to be able to retrieve both upstream and downstream of the processing phases;

3. the partners involved.

Production chain tracing calls for an updated, filed and readily available registration of all the pieces of information related to the activities and to the flows of the productive process. Once the perimeter of the tracking system has been defined, together with the pieces of information to be carried throughout the chain, it is necessary to define the tool to be used to retrieve (identification) and vehicle (communication) the pieces of information in question. The development of the technical aspects and the description of the procedures should occur in parallel. The tool should be adapted to the organization and the other way round. Broadly speaking, the description of how a traceability system should be organized cannot fail to neglect some correlated aspects:

Fig. 8 - Software display during data loading. 
Technical functions: technical translation of the operations, description of the data categories, of the descriptive data and of the codification standard;

Technical constraints and performance: reliability, rapidity, updating potentials, amount of information to be processed, storage duration, frequency of changes in information, possibility of dialoguing with other systems, environment and human resources, etc.;

Hardware configuration: tools (scanners, printers, software applications, EDI workstations, etc.) Traceability implies data storage along the entire chain.

This calls for technological devices designed to codify, read and store data and implement an information system to forward, process and re-forward the above data.

In other to, a company or an organization's assets are largely stored as digital format in online relational databases. Database security is a crucial element in the assets management of nowadays enterprise.

To protect database is to protect access to a company's sensitive information and digital assets.

Database is a complex system and very difficult to manage and to ensures confidentiality, availability, integrity. Database security can be controlled at different layers. Auditing is critical, but analysis is hard. Future analytical tools will be a great help.

There are many layers to protect an on line relational database. Those layers should cooperate together to get secure strengthened.

Authentication and encryption play a very important role in database security.

In conclusion, as already mentioned, the study carried out has been intended to detect any mismatches, i.e. errors of manipulation or of registration likely to compromise the identification of the product traced in a view to suppressing any sources of risk in compliance with the requirements of EC Reg. 178/2002.

The work, therefore, is focused on the analysis and the use of both tracking and tracing systems of olive and olive oil products throughout the entire territory of Calabria. The present study has been based on an in-depth analysis of the area under consideration in a view to identifying some farms typical of the territory in question. The different steps of olive processing have been analyzed, from olive harvesting to olive processing at the oil mill.

A detailed analysis of the productive processes has been made possible through the definition of the socalled "dynamic lot": a unit of product processed (either directly or indirectly) in a time unit (usually a day), as a function of the peculiarities of the olive growing farms involved (orographic features, level of mechanization, etc.).

The data obtained have allowed to implement a specific software which allows for a comprehensive monitoring of all the processing and production phases:

- acquiring data (input) related to the olive growing sector under study;

- implementing (output) innovative labelling systems (barcode labels) that enable workers to process information very rapidly and obtain exhaustive data concerning the origin of the product in question.

\section{References}

[1] "Regolamento (CE) N N $^{\circ}$ 178/2002", Gazzetta Ufficiale delle Comunità europee del 28 gennaio 2002.

[2] Atti "ACCAdEMia DeI GeORGOFILI" Maggio 2000, Logge Uffizi Corti, Firenze.

[3] Meuwissen Miranda P.M., Velthuis Annet G.J., Hogeveen Henk, Huirne Rudd B.M. - "Technical and economic considerations about traceability and certification in livestock production chains". New Approaches to Food-Safety Economics Series: Wageningen UR Frontis Series, Vol. 1 Velthuis, A.G.J.; Unnevehr, L.J.; Hogeveen, H.; Huirne, R.B.M. (Eds.) 2003, 49-62., Hardcover.

[4] IRER, regione Lombardia "Importanza della tracciabilità, in una logica di forte identità delle produzioni agroalimentari della Lombardia, e conseguenti strategie di marketing da adottare relativamente alle principali filiere produttive Lombarde", Milano, maggio 2004.

[5] Sciarrone G., Abenavoli M.L., "La tracciabilità di filiera: un'opportunità per l'olivicoltura", IV Convegno AISSA: Qualità e sostenibilità delle produzioni agrarie, alimentari e forestali; Mosciano Sant'Angelo (TE), 5-6 dicembre 2006.

[6] Sciarrone G., Abenavoli L.M., Proto A.R., "Implementazione di un sistema di tracciabilità nella filiera olivicola: prime applicazioni”, IV Convegno AISSA: Qualità e sostenibilità delle produzioni agrarie, alimentari e forestali; Mosciano Sant'Angelo (TE), 5-6 dicembre 2006.

[7] Takato N., Asuka-Kyowa L., "Traceability system using RFID and Legal Issues", Wholes Conference, Stockholm, Sweden, gennaio 2004.

[8] HTTP://WWW.SNAPWEB.IT.

[9] Peupert M., Theuvsen L., "Tracking and tracing meat products - the role of modern information technologies", EFITA Conference, Debrecen, Hungary, 5-9 giugno 2003.

[10] Regolamento Ce 1531/2001 "Normativa e classificazione dell'olio d'oliva” 23 luglio 2001.

[11] HTTP://WWW.CDR-MEDIARED.IT/DIAGNOSTICA-ALIMENTARE.

\section{SUMMARY}

The indication of the "path" travelled by all European agrofood products has by now become compulsory: starting from January the 1st, 2005 EC Regulation 178/2002 has established the notions of food tracking and tracing as well as the concept of food safety. Food traceability and safety are becoming notions of crucial importance to those who work in this sector in view of their potentially positive influence on produce competitiveness and appreciation on the part of consumers. This specific line of research is focused on the analysis and the use of both tracking and tracing systems of olive and olive oil products 
throughout the entire territory of Calabria.

A detailed analysis of the productive processes has been made possible through the definition of the socalled "dynamic lot": a unit of product processed (either directly or indirectly) in a time unit (usually a day), as a function of the peculiarities of the olive growing farms involved (orographic features, level of mechanization, etc.).
The software architecture (which is currently being updated) has been studied considering the reality of the territory in question, and the average level of computer/software literacy of the operators asked to use it.

Key words:

Traceability, olive growing, quality, food safety. 